\title{
UGT1A1 gene and neonatal hyperbilirubinemia: a preliminary study from Bengkulu, Indonesia
}

\author{
Radhian Amandito 1,2, Raihandhana Putradista ${ }^{3}$, Clara Jikesya $^{3}$, Dwi Utaminingsih ${ }^{3}$, Jumnalis Rusin 4 , \\ Rinawati Rohsiswatmo 2,5 and Amarila Malik ${ }^{3^{*}}$ (1)
}

\begin{abstract}
Objective: The genetic involvement in unconjugated neonatal hyperbilirubinemia has been extensively studied. Despite the high incidence of hyperbilirubinemia in Indonesia, studies are lacking. The objective of this study is to elucidate the role of polymorphism in the UGT1A1 in Neonatal Hyperbilirubinemia in Bengkulu, Indonesia.

Results: There were 41 neonates enrolled in the study; 30 had a total serum bilirubin level $\geq 15 \mathrm{mg} / \mathrm{dL}$ (hyperbilirubinemia neonates) while 11 has $<15 \mathrm{mg} / \mathrm{dL}$ (control neonates). Genetic mutations in Exon 1, UGT1A1*6 (c211g $>a$ ) and one in promoter region, UGT1A ${ }^{*} 60$ (c3279t $>\mathrm{g}$ ) were determined by polymerase chain reaction-restriction fragment length polymorphism. We found 18 (60\%) mutation in exon 1 in hyperbilirubinemia group and 7 (64\%) in the control group with an identical allele frequency of 0.3 in both groups. We found heterozygous UGT1A1*60 4 times (13.3\%) and homozygous 26 times (86.7\%) in the hyperbilirubinemia group, with an identical allele frequency of 0.935 in hyperbilirubinemia and 1 in control group. This study supports the involvement of genetic factors in the development of unconjugated hyperbilirubinemia in Bengkulu population.
\end{abstract}

Keywords: Bilirubin, Glucuronosyltransferase, Indonesia, Neonatal hyperbilirubinemia, Restriction fragment length polymorphism

\section{Introduction}

Neonatal hyperbilirubinemia is a common condition in neonates caused by the combination of increased heme catabolism and physiologic immaturity of the liver in bilirubin conjugation and excretion [1]. This condition may lead to kernicterus, which causes disability and death [2]. Risk factors for hyperbilirubinemia have been determined, albeit with varying degrees. They range from $\mathrm{ABO}$ incompatibility, premature birth, breastfeeding, to genetic conditions such as G6PD deficiency and polymorphisms in UGT1A1 [3].

UDP-glucoronosyltransferase 1A1 (UGT1A1) is the key enzyme for bilirubin conjugation. It is mapped to the

\footnotetext{
*Correspondence: amarila.malik@ui.ac.id

${ }^{3}$ Division of Pharmaceutical Microbiology and Biotechnology, Faculty of Pharmacy, Universitas Indonesia, UI Depok Campus, Depok, West Java 16424, Indonesia

Full list of author information is available at the end of the article
}

chromosome 2q37 [4]. A variety of allelic polymorphisms of human UGT1A1 have been reported, with some leading to partial or complete deficiency of enzyme activity [5].

The UGT1A1*6 (c211G > A) mutation in exon 1, which causes decreased enzyme activity, was found to be associated with neonatal hyperbilirubinemia in Asian populations, as well as one of the most prevalent polymorphism in East Asian population [6]. The UGT1A1*60 $(\mathrm{c}-3279 \mathrm{~T}>\mathrm{G})$ mutation in promoter region was found to be a frequent mutation in the Egyptian neonates with neonatal hyperbilirubinemia [7].

Despite a study by Sutomo on Indonesian population, study on different ethnic populations of Indonesia for polymorphism of the $U G T 1 A 1$ gene is needed [8]. In the ethnic group of Indonesia in Bengkulu, a high number of neonatal hyperbilirubinemia was reported by the Provincial Referral Hospital in the year 2016; 80 out of 362 
neonates treated in the NICU. In addition, Bengkulu with an area of approximately $20,000 \mathrm{~km}^{2}$ and a population of fewer than 2 million people is isolated in terms of ethnic diversity, making it an ideal location to study ethnicrelated polymorphism. To gather more information on UGT1A1 gene variation in Indonesia, we investigated the association between UGT1A1*60 and UGT1A1*6 in Bengkulu neonates.

\section{Main text \\ Materials and methods \\ Study population}

This cross-sectional study was conducted in neonatal intensive care unit of M. Yunus General Hospital, Bengkulu, Indonesia. The study was approved by the Health Research Ethics Committee-University of Indonesia and national referral hospital Cipto Mangunkusumo, Jakarta. Data collection was conducted from November 2016 to February 2017. A written informed consent was obtained from the parents before inclusion into the study. Sample size calculation was done by Total Population Sampling due to the low number of population available within the set amount of time. The study population included 30 infants with hyperbilirubinemia (cases) and 11 infants as controls, which includes all eligible population. Both preterm and term neonates were assessed for eligibility.

Hyperbilirubinemia was determined from the total plasma bilirubin (TPB) of neonates patient obtained by using Bilistick [9] between 3 and 7 days of birth. Neonates were divided according to TPB in high risk hyperbilirubinemia ( $\geq 15 \mathrm{mg} / \mathrm{dL}$ ) or low risk, control infants $(<15 \mathrm{mg} / \mathrm{dL})$ [10]. Neonates with evidence of hemolysis (fall in Hemoglobin), phototherapy, blood transfusion or exchange transfusion, sepsis, asphyxia, cephalhematoma, and major congenital malformations were excluded. All neonates were recorded in terms of sociodemographic and clinical variables through clinical examination and laboratory investigations, as well as a review of the patient's medical record for previously obtained data of birth records.

\section{Laboratory investigations}

We performed blood examination. TPB was obtained by Bilistick device [9] and hemoglobin, hematocrite, platelets, and leukocyte count with standard lab technique. In addition, $1 \mathrm{~mL}$ of venous blood was collected in a vial containing EDTA for DNA extraction. Prior to DNA extraction, the blood samples were stored at $-20^{\circ} \mathrm{C}$. All DNA samples were analyzed for mutations in the promoter region and exon 1 of UGT1A 1 gene by polymerase chain reaction-restriction fragment length polymorphism (PCR-RFLP) method [11].

\section{Genomic DNA extraction and polymerase chain reaction}

Genomic DNA was extracted from both blood samples by using QIAamp DNA Blood Mini Kit (QIAGEN, Germany) according to the manufacturer. Genomic DNA as much as $2 \mathrm{ml}$ was added to a PCR mix con-

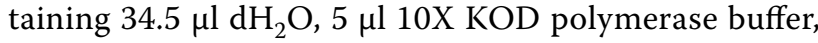
4 l $25 \mathrm{mM} \mathrm{MgSO}_{4}, 7 \mu \mathrm{l} 2 \mathrm{mM}$ dNTPs (dATP, dCTP, dGTP, dTTP), and $0.7 \mu \mathrm{l}$ KOD polymerase (Novagen, Germany). PCR amplification consisted of an initial denaturation of $2 \mathrm{~min}$ at $95{ }^{\circ} \mathrm{C}$ followed by 30 cycles of denaturation of $94{ }^{\circ} \mathrm{C}$ for $30 \mathrm{~s}$, annealing at $55{ }^{\circ} \mathrm{C}$ for $15 \mathrm{~s}$, extension at $72{ }^{\circ} \mathrm{C}$ for $1 \mathrm{~min}$, post extension at $72{ }^{\circ} \mathrm{C}$ for $5 \mathrm{~min}$ and hold at $4{ }^{\circ} \mathrm{C}$ for $60 \mathrm{~min}$. PCR reactions were carried out in a PCR thermocycler (Biometra, Germany). All PCR products were analyzed on $2 \%$ Ethidium bromide (EtBr) containing agarose gel in $1 \mathrm{x}$ TAE buffer, whereas for the detection of $\mathrm{c}-211 \mathrm{G}>\mathrm{A}$ mutation on the Exon 1 and $\mathrm{c}-3279 \mathrm{~T}>\mathrm{G}$ mutation on the promoter region of UGT1A1 gene, 3\% EtBr gel in 1 $x$ TBE were used.

\section{Detection of UGT1A1*6}

We used the restriction enzyme AvaII (NEB, USA) and amplified the exon 1 of $U G T 1 A 1$ gene by using primers UGT1A1_exon1Fw (U1F1 forward) 5'-AGATACTGT TGATCCCAGTG-3' and UGT1A1_exon1Rv (U211R reverse): 5'-CTTCAAGGTGTAAAATGCTC-3 according to a previous study [12].

\section{Detection of UGT1A $1 * 60$}

We used the restriction enzyme DraI (NEB, USA) and amplified the promoter region of UGT1A1 gene by using primers UGT1A1_promoter Fw (forward) 5'-CAC-CAGAACAAACTTCTGAG-3' and UGT1A1_promoter Rv (reverse) 5'-CTGTCCCTTCTG AAT-CATTG-3' to detect the mutation $\mathrm{c}-3279 \mathrm{~T}>\mathrm{G}$ according to the primer reported in a previous study [8].

\section{Statistical analysis}

Categorical independent variables and the categorical dependent variable were analyzed using Fishers exact test, while numerical dependent variables and categorical dependent variable were analyzed using student's t-test to see the association between the independent variables and dependent variable. Categorical variables were presented as percentages (sex, Breastfeeding, delivery method, sibling history of hyperbilirubinemia requiring phototherapy, primipara mother, race, $\mathrm{c} 211 \mathrm{G}>\mathrm{A}$ mutation, and $\mathrm{c}-3279 \mathrm{~T}>\mathrm{G}$ mutation), while numerical variables were expressed as mean and range (Gestational age, birth weight, and total plasma 
bilirubin). The software STATA ver 12 for macOS was used.

\section{Results}

\section{Demographic and clinical characteristics}

Forty-one term and preterm infants with total plasma bilirubin concentration of $\geq 15 \mathrm{mg} / \mathrm{dL}$ (high risk) or $<15 \mathrm{mg} / \mathrm{dL}$ (low risk) were enrolled. The clinical characteristics of the patients are reported in Table 1. The peak bilirubin level in high risk hyperbilirubinemia was $29 \mathrm{mg} /$ $\mathrm{dL}$. The risk of developing high risk hyperbilirubinemia for each risk factors were estimated by either fishers exact test or student's t test. None of the studied clinical risk factors were associated with high-risk hyperbilirubinemia; breastfeeding (OR 1.77; 95\% CI 0.329-12.347), vaginal vs cesarean delivery method (OR 1.75; 95\% CI 0.348-9.829), sibling history for hyperbilirubinemia requiring phototherapy (OR 0.155 ; 95\% CI $0.003-3.491$ ), and primipara mother (OR 2.66; 95\% CI 0.497-18.229). These findings are in line with a study that suggested not all neonates with hyperbilirubinemia have the known risk factors present [13], suggesting a different dominant risk factor is involved in different populations. Since our study was homogenous and low in samples, the tendency for our different findings was expected.

Premature birth also did not show association with high-risk hyperbilirubinemia. It is known that UGT1A1 is modulated progressively according to gestational age, from $0.1 \%$ at $17-30$ weeks' gestation to $1 \%$ at $30-40$ weeks' gestation and reach adult levels by 14 weeks postnatal [14]. This shows that premature infants could aggravate the immaturity of the conjugating enzyme, thus causing a more severe hyperbilirubinemia, in addition to the exaggerated neonatal red cell, hepatic, and gastrointestinal immaturity. This suggests that despite the risk for hyperbilirubinemia, premature birth does not necessarily cause higher levels of bilirubin by itself as the risk factor.

\section{Detection of UGT1A1 mutation}

Table 2 shows the distribution of $U G T 1 A 1$ variants of both the exon 1 and promoter mutation, and the allele variant. In high-risk hyperbilirubinemia neonates, the incidence of wild type (no risk for hyperbilirubinemia) was instead higher (40-36\%) than UGT1A1*6 is $(60-64 \%)$. While for $U G T 1 A 1 * 60$, there was no wild type detected in either group, small incidence of

Table 1 Clinical characteristics of study group

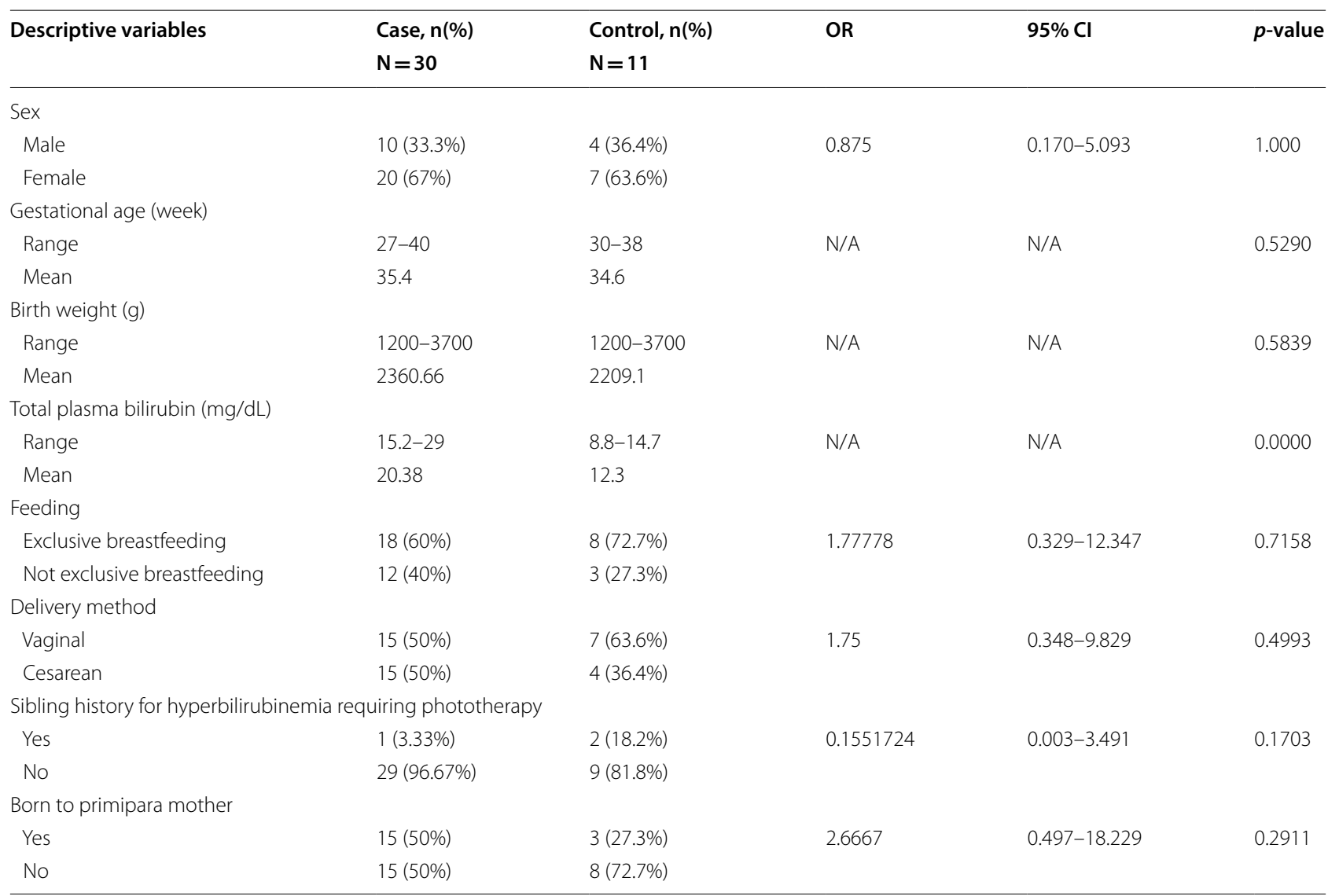


Table 2 Distribution of UGT1A1 variants

\begin{tabular}{lll}
\hline Mutation & $\begin{array}{l}\text { Case, } \mathbf{n}(\%) \\
\mathbf{N}=\mathbf{3 0}\end{array}$ & $\begin{array}{l}\text { Control, } \mathbf{n}(\%) \\
\mathbf{N}=\mathbf{1 1}\end{array}$ \\
\hline UGT1A1*6 $^{*}$ & $12(40 \%)$ & $4(36 \%)$ \\
GG & $18(60 \%)$ & $7(64 \%)$ \\
GA & $0(0 \%)$ & $0(0 \%)$ \\
AA & 0.3 & 0.32 \\
A Allele & \\
UGT1A1*60 & $0(0 \%)$ & $0(0 \%)$ \\
TT & $4(13 \%)$ & $0(0 \%)$ \\
TG & $26(87 \%)$ & $11(100 \%)$ \\
GG & 0.935 & 1 \\
G Allele & &
\end{tabular}

Table 3 Mutation variant distribution in study group

\begin{tabular}{lll}
\hline Variation & Case, $\mathbf{n}(\%)$ & Control, $\mathbf{n}(\%)$ \\
& $\mathbf{N}=\mathbf{3 0}$ & $\mathbf{N}=\mathbf{1 1}$ \\
\hline GG/TG & $3(10 \%)$ & $0(0 \%)$ \\
GG/GG & $9(30 \%)$ & $4(36 \%)$ \\
GA/TG & $1(3.3 \%)$ & $0(0 \%)$ \\
GA/GG & $17(57 \%)$ & $7(65 \%)$ \\
\hline
\end{tabular}

heterozygous form in high risk hyperbilirubinemia (13\%), and higher incidence of homozygous form in low risk hyperbilirubinemia group (87-100\%). There was no association between high risk and low risk hyperbilirubinemia groups' polymorphism status as shown by the statistical analysis.

\section{Association between UGT1A1 mutation and unconjugated hyperbilirubinemia}

As reported in Chinese neonates [15], the possible synergistic effect of more than one mutation on TPB was investigated in our series (Table 3 ). The occurrence of multiple mutation varies in high risk and low risk hyperbilirubinemia groups. In high risk hyperbilirubinemia group, there is more incidence of wild type exon 1 with heterozygous UGT1A1*60 (GG/TG; $10-0 \%)$ and heterozygous $U G T 1 A 1 * 6$ with heterozygous UGT1A1*60 (GA/TG; 3.3-0\%) compared to low risk hyperbilirubinemia. While in low risk group there is more incidence of wild type exon 1 with homozygous UGT1A1*60 (GG/GG; 30-36\%) and heterozygous UGT1A1*6 with homozygous UGT1A1*60 (GA/ GG; $57-65 \%)$. There was no association between multiple mutation sites of UGT1A1 and high or low risk hyperbilirubinemia.

\section{Discussion}

From previous studies in Javanese Indonesians and Malays, which are anthropologically closely related with Bengkulu Indonesians, the frequency of mutation of UGT1A1*6 (0.015 and 0.014) is quite low and does not differ significantly between normal bilirubin level and hyperbilirubinemia neonates [7]. This figure is similar to an Indian study with a frequency of 0.03 for hyperbilirubinemic neonates and 0.002 for healthy neonates [16]. Therefore, it can be concluded that despite being particularly frequent in East Asian population, UGT1A1*6, does not contribute to the development and/or severity of hyperbilirubinemia. In contrast to previous findings [7], our study found a relatively high incidence of UGT1A1*6 mutation in Bengkulu Indonesian population in both hyperbilirubinemia and normal bilirubin neonate, compared to the frequency in other populations $(0.3$ and 0.32 respectively). This discrepancy could be accounted by the more homogenous ethnicity and isolated population of Bengkulu and by a difference in sample size. Despite the high prevalence of the mutation, it is not a specific risk factor to the development of high risk neonatal hyperbilirubinemia with a high level of bilirubin in Bengkulu population.

UGT1A1*60 decreases the transcriptional activity of UGT1A1 by $60 \%$ [17]. A study on Malaysian neonates [18] concluded that the allele frequency of UGT1A1*60 was significantly higher in hyperbilirubinemia neonates when compared to controls. Between the homozygous and heterozygous group of case and control, the heterozygous cases were not significantly different compared to the heterozygous controls, suggesting that presence only of the UGT1A1*60 does not per se cause neonatal hyperbilirubinemia, but rather is a risk factor to this condition. Similar findings were reported in Egyptian neonates [8]. The allele frequency of UGT1A1*60 in Egyptian neonates was $49.2 \%$ for the hyperbilirubinemia group and 25.6\% for the control group, while in East Asian neonates the frequency is lower ranging from $25 \%$ [19] to $27 \%$ [20].

Our findings are in line with the ethnically similar population of Malaysian neonates [18] and the Egyptian [8], with allele frequency of 0.935 in high risk hyperbilirubinemic neonates and 1 in controls. Despite the high frequency between both groups, the difference is not statistically significant, even for the high frequency in the control group. This suggests that mutation in the promoter region alone does not cause high risk hyperbilirubinemia in Bengkulu neonates.

It has been previously shown that not one, but several mutations are involved in causing the non-physiologic hyperbilirubinemia in neonates $[15,16]$. In contrast to previous studies, no specific combination of risk factor were observed even with the combination of the 2 
highest risk mutation variant found in our group (GA/ GG). This data suggests a different combination of clinical and genetic factors for Bengkulu neonates compared to other races.

Although hyperbilirubinemia is common, in Indonesia, the number of kernicterus cases reported are rather small. In addition, the causes of these severe cases are unknown. Accordingly, a study into other possible etiologies including genetic risk factors in Indonesian neonatal hyperbilirubinemia is necessary.

\section{Conclusion}

In Bengkulu neonates, both mutation $U G T 1 A 1 * 6$ and UGT1A1*60 was found in hyperbilirubinemic neonates but they do not act as individual risk factors to the severity of the neonatal hyperbilirubinemia. Therefore, the high incidence of neonatal hyperbilirubinemia in Bengkulu is not solely caused by UGT1A1*6 nor UGT1A1*60 polymorphism. Further studies are necessary with more sample size and inclusion of other polymorphisms.

\section{Limitations}

We limited our study to two mutations that are commonly found in Asian neonates. We also used only neonates of Bengkulu descendant, with no comparison with non-Bengkulu Indonesians. The available population from the set of time determined was low thus statistical bias was possible.

\section{Abbreviations}

TPB: total plasma bilirubin; PCR-RFLP: polymerase chain reaction-restriction fragment length polymorphism; UGT1A1: UDP-glucoronosyltransferase 1A1.

\section{Authors' contributions}

This work was carried out in collaboration between all authors. RA, RR and AM designed the study; RA and JR acquired the data; RP, CJ, DU, and AM performed experiments. RA, RP, CJ, RR, DU, and AM analysed the data; RA, RP, and $C J$ wrote the manuscript; JR, DU, RR, and AM gave technical support and conceptual advice. All authors read and approved the final manuscript.

\section{Author details \\ ${ }^{1}$ M Yunus General Hospital, Jl Bhayangkara, Bengkulu City, Bengkulu, Indone- sia. ${ }^{2}$ Neonatal Intensive Care Unit, Pondok Indah General Hospital, J Metro Duta Kav. UE, Pondok Indah, Jakarta, Indonesia. ${ }^{3}$ Division of Pharmaceutical Microbiology and Biotechnology, Faculty of Pharmacy, Universitas Indone- sia, UI Depok Campus, Depok, West Java 16424, Indonesia. ${ }^{4}$ Department of Pediatrics, M Yunus General Hospital, Jl Bhayangkara, Bengkulu City, Beng- kulu, Indonesia. ${ }^{5}$ Division of Perinatology, Department of Pediatrics, Cipto Mangunkusumo General Hospital, Faculty of Medicine, Universitas Indonesia, JI Pangeran Diponegoro No. 71, Central Jakarta, Jakarta, Indonesia.}

\section{Acknowledgements}

We would like to thank C. Tiribelli and CC. Zabetta for supplying us with Bilistick device and R. Maulida, Faculty of Public Health, Universitas Indonesia for assistance in statistical analysis.

\section{Competing interests}

The authors declared that they have no competing interests.

\section{Availability of data and materials}

The datasets used and/or analysed during the current study are available from the corresponding author on reasonable request.

\section{Consent to publish}

No individual data was published in this manuscript.

\section{Ethics approval and consent to participate}

All authors hereby declare that all experiments have been examined and approved by the Ethics Committee of the Faculty of Medicine, Universitas Indonesia (No. 995/UN2.F1/ETIK/2016, Protocol Number 16-11-432) and have therefore been performed in accordance with the ethical standards laid down in the 1964 Declaration of Helsinki. A written informed consent was obtained from the parents before inclusion into the study.

\section{Funding}

Funding was supported by Hibah PUPT 2017 Research Grant from Directorate for Higher Education, Republic of Indonesia to A.M. and R.R (No. 2601/ UN2.R3.1/HKP05.00/2017). The funding body has no role in the design of the study and collection, analysis, nor interpretation of data and in writing the manuscript.

\section{Publisher's Note}

Springer Nature remains neutral with regard to jurisdictional claims in published maps and institutional affiliations.

Received: 13 October 2017 Accepted: 7 March 2018

Published online: 13 March 2018

\section{References}

1. Dennery PA, Seidman DS, Stevenson DK. Neonatal hyperbilirubinemia. N Engl J Med. 2001;344(8):581-90.

2. Kaplan M, Hammerman C. Understanding severe hyperbilirubinemia and preventing kernicterus: adjuncts in the interpretation of neonatal serum bilirubin. Clin Chim Acta. 2005;356(1-2):9-21.

3. Huang M-J, Kua K-E, Teng H-C, Tang K-S, Weng H-W, Huang C-S. Risk factors for severe hyperbilirubinemia in neonates. Pediatr Res. 2004;56(5):682-9.

4. Gong QH, Cho JW, Huang T, et al. Thirteen UDPglucuronosyltransferase genes are encoded at the human UGT1 gene complex locus. Pharmacogenetics. 2001;11(4):357-68.

5. Costa E. Hematologically important mutations: bilirubin UDP-glucuronosyltransferase gene mutations in Gilbert and Crigler-Najjar syndromes. Blood Cells Mol Dis. 2006;36(1):77-80.

6. Jinno H, Tanaka-Kagawa T, Hanioka N, et al. Glucuronidation of 7-ethyl10-hydroxycamptothecin (SN-38), an active metabolite of irinotecan (CPT-11), by human UGT1A1 variants, G71R, P229Q, and Y486D. Drug Metab Dispos. 2003;31(1):108-13.

7. Sutomo R, Talib NA, Yusoff NM, et al. Screening for G71R mutation of the UGT1A1 gene in the Javanese-Indonesian and Malay-Malaysian populations. Pediatr Int. 2004;46(5):565-9.

8. Tomerak RH, Helal NF, Shaker OG, Yousef MA. Association between the specific UGT1A1 promoter sequence variant (c-3279T > G) and unconjugated neonatal hyperbilirubinemia. J Trop Pediatr. 2016;62(6):457-63.

9. Coda Zabetta CD, Iskander IF, Greco C, et al. Bilistick: a low-cost point-of-care system to measure total plasma bilirubin. Neonatology. 2013;103(3):177-81.

10. Maisels MJ, Bhutani VK, Bogen D, Newman TB, Stark AR, Watchko JF. Hyperbilirubinemia in the newborn infant $\geq 35$ weeks' gestation: an update with clarifications. Pediatrics. 2009;124(4):1193-8.

11. Rasmussen HB. Restriction fragment length polymorphism analysis of PCR-amplified fragments (PCR-RFLP) and gel electrophoresis-valuable tool for genotyping and genetic fingerprinting. In Gel electrophoresisprinciples and basics. Houston: InTech; 2012.

12. Agrawal SK, Kumar P, Rathi R, et al. UGT1A1 gene polymorphisms in North Indian neonates presenting with unconjugated hyperbilirubinemia. Pediatr Res. 2009;65(6):675-80. 
13. Maruo Y, Nishizawa K, Sato H, Doida Y, Shimada M. Association of neonatal hyperbilirubinemia with bilirubin UDP-glucuronosyltransferase polymorphism. Pediatrics. 1999;103(6):1224-7.

14. Kawade N, Onishi S. The prenatal and postnatal development of UDP-glucuronyltransferase activity towards bilirubin and the effect of premature birth on this activity in the human liver. Biochem J. 1981;196(1):257-60.

15. Yang $H$, Wang $Q$, Zheng $L$, et al. Clinical significance of UGT1A1 genetic analysis in Chinese neonates with severe hyperbilirubinemia. Pediatr Neonatol. 2016;57(4):310-7.

16. Tiwari P, Bhutada A, Agarwal R, Basu S, Raman R, Kumar A. UGT1A1 gene variants and clinical risk factors modulate hyperbilirubinemia risk in newborns. J Perinatol. 2014;34(2):120-4.

17. Sugatani J, Mizushima K, Osabe M, et al. Transcriptional regulation of human UGT1A1 gene expression through distal and proximal promoter motifs: implication of defects in the UGT1A1 gene promoter. Naunyn Schmiedeberg's Archiv Pharmacol. 2008;377(4-6):597-605.

18. Yusoff S, Takeuchi A, Ashi C, et al. A polymorphic mutation, c.-3279T > G, in the UGT1A1 promoter is a risk factor for neonatal jaundice in the Malay population. Pediatr Res. 2010;67(4):401-6.

19. Kaniwa N, Kurose $K$, Jinno $H$, et al. Racial variability in haplotype frequencies of UGT1A1 and glucuronidation activity of a novel single nucleotide polymorphism 686C > T (P229L) found in an African-American. Drug Metab Dispos. 2005;33(3):458-65.

20. Ki C-S, Lee K-A, Lee S-Y, et al. Haplotype structure of the UDP-glucuronosyltransferase 1A1 (UGT1A1) gene and its relationship to serum total bilirubin concentration in a male Korean population. Clin Chem. 2003:49(12):2078-81.

\section{Submit your next manuscript to BioMed Central and we will help you at every step:}

- We accept pre-submission inquiries

- Our selector tool helps you to find the most relevant journal

- We provide round the clock customer support

- Convenient online submission

- Thorough peer review

- Inclusion in PubMed and all major indexing services

- Maximum visibility for your research

Submit your manuscript at www.biomedcentral com/submit 